\title{
Ender Rastlanan Bir Tümör: Alt Ekstremitede Hemanjioperisitoma
}

\author{
Murat Uğurlucan $^{1} \oplus$, Kaan Altunyuva ${ }^{2} \odot$, Didem Melis Öztaş ${ }^{\oplus}$, Eren Özgür ${ }^{3} \oplus$, \\ Muzaffer Ümütlü̈ ${ }^{4}$, Evşen Apaydın ${ }^{5}$, Nilgün Bozbuğa ${ }^{6} \odot$, Ufuk Alpagut ${ }^{6} \odot$
}

'İstanbul Medipol Üniversitesi, Tıp Fakültesi, Kalp ve Damar Cerrahisi Anabilim Dalı, İstanbul, Türkiye Bağcılar Eğitim Araştırma Hastanesi, Kalp ve Damar Cerrahisi Kliniği, İstanbul, Türkiye

${ }^{3}$ Doğubeyazıt Devlet Hastanesi, Radyoloji, Ağrı, Türkiye 4İstanbul Üniversitesi İstanbul Tıp Fakültesi, Radyoloji Anabilim Dalı, İstanbul, Türkiye

${ }^{5}$ Hatay Devlet Hastanesi, Tibbi Patoloji, Hatay, Türkiye

${ }^{6}$ Istanbul Üniversitesi İstanbul Tıp Fakültesi, Kalp ve Damar Cerrahisi Anabilim Dalı, İstanbul, Türkiye

Murat Uğurlucan, Doç. Dr. Kaan Altunyuva, Op. Dr. Didem Melis Öztaş, Op. Dr. Eren Özgür, Dr.

Muzaffer Ümütlü, Dr.

Evşen Apaydın, Dr.

Nilgün Bozbuğa, Prof. Dr.

Ufuk Alpagut, Prof. Dr.

\section{İletişim:}

Doç. Dr. Murat Ugurlucan

İstanbul Medipol Üniversitesi Tip Fakültesi, Kalp ve Damar Cerrahisi Anabilim Dalı, TEM Avrupa Otoyolu Göztepe Çıkışı, No: 1, Bağcılar 34214, İstanbul, Türkiye

Tel: +905308251122

E-Posta: muratugurlucan@yahoo.com

Gönderilme Tarihi : 22 Haziran 2018

Revizyon Tarihi : 02 0cak 2019

Kabul Tarihi : : 08 Mayıs 2019

\section{ÖZET}

Hemanjioperisitomalar, kapiller duvarında yer alan perisitlerden köken alan yumuşak doku tümörlerindendir. Genelde selim seyretmekle birlikte agresif seyreden formları da vardır. İnsan vücudunda her yerde görülebilmelerine rağmen retroperiton en sık görüldüğü yerdir. Tedavi seçenekleri arasında cerrahi yaklaşımlar ilk seçenek olmakla birlikte nadiren radyoterapi ve kemoterapi de kullanılmaktadır. Biz bu yazıda kliniğimizde cerrahi olarak tedavisini uyguladığımız femoral bölgede yerleşimli hemanjioperisitoma olgusunu sunmaktayız.

Anahtar sözcükler: Hemanjioperisitoma, Alt Ekstremite, Cerrrahi Tedavi

\section{A RARE TUMOR: HEMANGIOPERICYTOMA OF THE LOWER EXTREMITY}

\section{ABSTRACT}

Hemangiopericytoma is a soft tissue tumor that originates from the pericytes in the walls of capillaries. Although there are aggressive forms of the tumor, the course is generally benign. The tumor may occur anywhere in the human body; however, the most common location is the retroperitoneum. Surgical approaches are the first choice among treatment options; however, radiotherapy and chemotherapy can rarely be applied. In this report, we present a case of hemangiopericytoma that is located in the femoral region which underwent surgical therapy at our institution.

Keywords: Hemangiopericytoma, Lower extremity, Surgical Therapy

$\mathrm{H}$ emanjioperisitomalar, kapiller ve venüller arasında uzanan perisitlerden köken alan malign yumuşak doku tümörlerindendir. Çoğunlukla selim seyretmekle birlikte agresif seyreden formları da bulunur. Bu tümör ilk olarak 1937'de Schmidt tarafından tespit edilmiş, 1942'de Stout ve Murray tarafından tamamen tanımlanmıştır (1). Son zamanlarda perisitik diferansiasyonun çok az olguda gösterilmesi sebebiyle yeni sınıflamada "soliter fibröz tümör" tanısı gündeme gelmiştir (2).

Vücutta herhangi bir lokalizasyonda görülebilirler. En sık görüldüğü yer alt ekstremiteler (özellikle bacaklar) ve retroperitondur. Tanı koyulan hastaların \%30-50'sinde alt ekstremite tutulumu mevcuttur (3). Ortalama görülme yaşı sıklıkla 45-55 yaş arasında değişmekte olup, erkekler ve kadınlar arasında eşit bir dağılım gözlenmektedir (1).

İyi kapsüllenmiş hipervasküler bir tümör olan hemanjioperisitomanın histopatolojik incelemesinde iğsi ya da yuvarlak hücre grupları ve kitleleri ile sarılmış çok sayıda kapiller ve büyük sinüzoidal boşluklar görülmektedir (1). Bu tümörler invaziv ve vaskülarizasyon 
açısından oldukça zengin olup, nüks edebilirler ve $\% 50$ kadarı akciğerler, kemik ve karaciğere metastaz yapabilir (4).

Tedavi seçenekleri arasında cerrahi yaklaşımlar ilk seçenek olmakla birlikte, nadiren radyoterapi ve kemoterapi de kullanılmaktadır. Biz bu yazıda kliniğimizde cerrahi olarak tedavisini uyguladığımız femoral bölgede yerleşimli hemanjioperisitoma olgusunu sunmaktayız.

\section{Olgu sunumu}

Altmış sekiz yaşında kadın hasta 1,5 senedir olan sağ alt ekstremite ve kasık ağrısı sebebiyle başvurduğu merkezde yapılan incelemeler sonucunda, sağ femoral lojda kitle ve yapılan biyopsi sonucuna göre hemanjioperisitoma saptanması üzerine kliniğimize başvurdu. Hastanın öyküsünde hipertansiyon, hiperlipidemi ve diabet mevcuttu ve medikal tedavisi ilgili branşlarca düzenlenmişti. Hasta obezdi (BMl: 29,4 kg/m²) Soy geçmişinde herhangi bir özellik yoktu. 30 paket/yıl sigara kullanım öyküsü mevcuttu.

Fizik muayenede sağ femoral lojda inspeksiyon ile belli olmayan ancak palpasyon ile hissedilebilen yaklaşık $4,5 \times 6 \mathrm{~cm}$ boyutlarında, sınırlı, mobil olmayan kitle palpe edildi. Bilateral tüm nabızları palpe idi. Çekilen bilgisayarlı tomografi (BT) anjiyografide femoral kitlenin sınırları, femoral arter ve ven ile olan komşuluğu ve kitleyi besleyen vasküler dallar görülmekteydi (Şekil 1a, Şekil 1b).

Hastanın uzun süredir var olan şikâyetleri, kitlenin vasküler yapılara yakınlığı ve bası semptomları göz önüne alınarak cerrahi eksizyon kararı alındı. Hastaya, tedavi yöntemi hakkında bilgi verildi, riskler ve faydalar anlatılarak hastanın onamı alındı.

Operasyon genel anestezi altında yapıldı. Sağ femoral insizyon ile tümöre ulaşıldı, kitlenin çevre dokulara olan yapışıkıkları dikkatlice ayrıldı (Şekil 2a). Damar invazyonu olmadığı görüldü. Çevre dokulara ve tümöral kitleye yapışık olan patolojik lenf nodları çıkartıldı. Ana femoral arter ve yüzeyel femoral arterden orijin alan ve kitleyi besleyen arteryel yapıların tamamı ligatüre edilerek divize edildi. Vastus medialis ve sartorius kas grupları arasında bulunan yaklaşık $4,5 \times 5 \mathrm{~cm}$ boyutundaki tümör dokusu vasküler yapılardan tamamen ayrılarak eksize edildi (Şekil 2b). Materyal (Şekil 2c) histopatolojik inceleme amacıyla patoloji anabilim dalına gönderildi. Herhangi bir komplikasyonla karşılaşılmadı ve operasyon sonlandıııldı.

Operasyon sonrası hastanın şikâyetlerinin azaldığı, takiplerde tamamen kaybolduğu gözlendi. Hasta postoperatif 3.
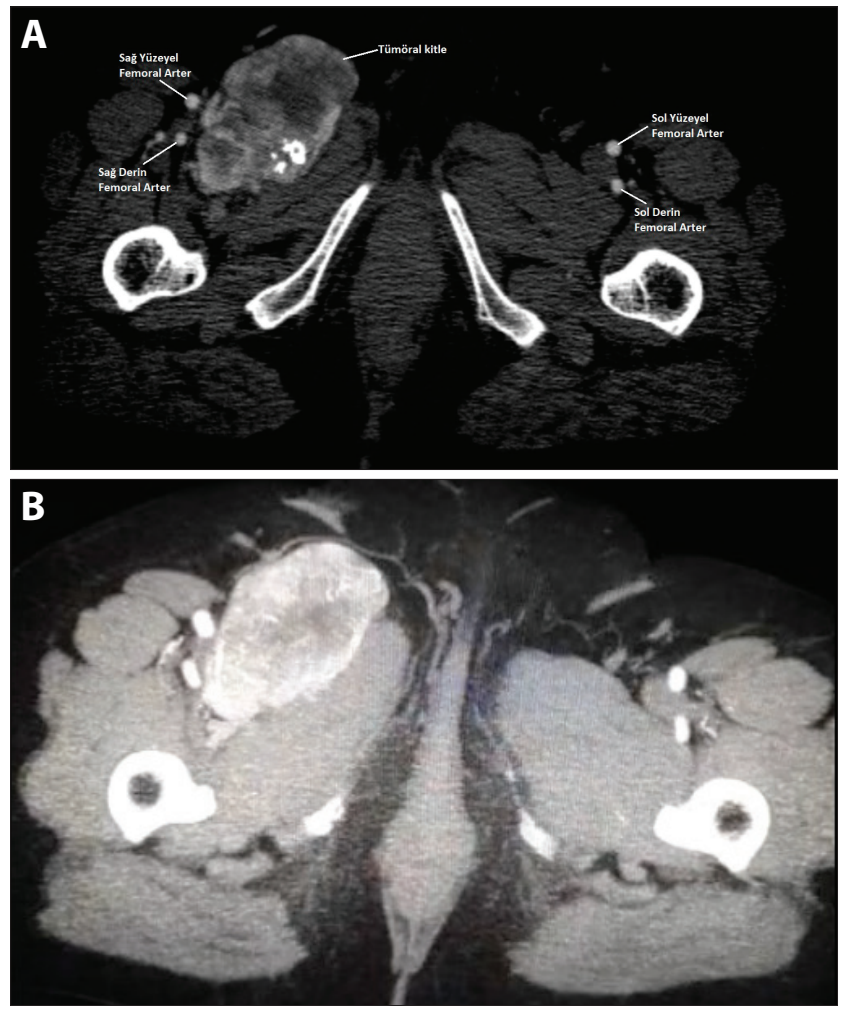

Şekil 1. a, b. Preoperatif BT anjiyografi görüntüsü. Femoral kitlenin sınırları, femoral arter ve ven ile olan komşuluğu görülmektedir (a). Preoperatif BT anjiyografi görüntüsü (venöz faz) (b).
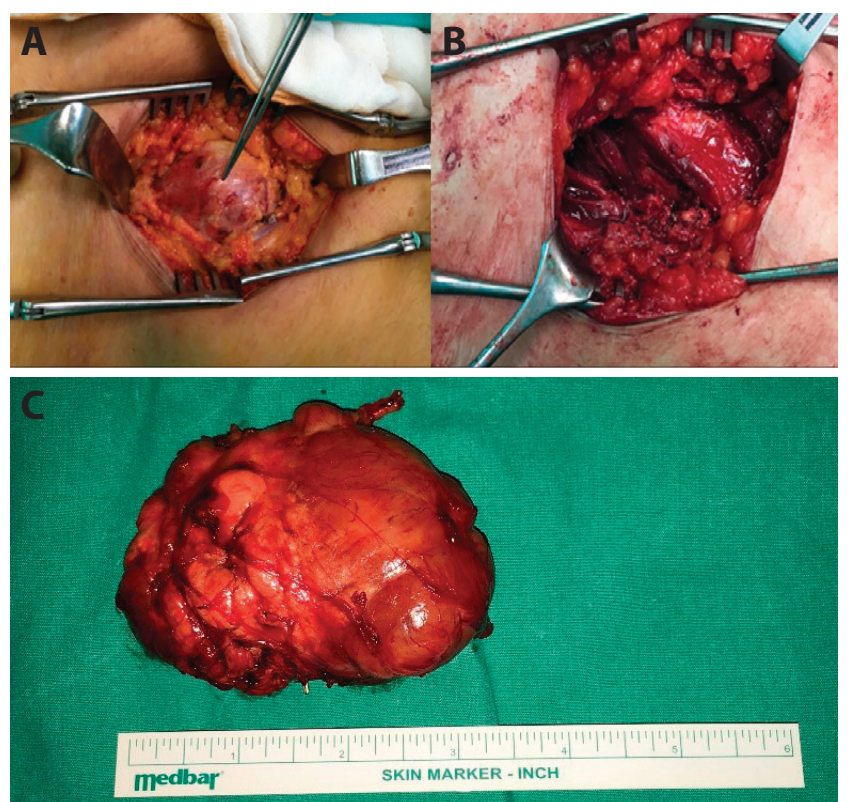

Şekil 2. a-c. Tümöral kitlenin peroperatif görüntüsü (a). Kitlenin eksizyonu sonrası femoral lojun peroperatif görüntüsü (b). Eksize edilen tümöral kitle (c).

gününde sorunsuz olarak taburcu edildi. Patoloji birimine gönderilen kitlenin inceleme sonucu hemanjioperisitoma (Şekil 3) ile uyumlu bulundu ve hasta gerekli takip ve tedavinin yapılması amacı ile onkoloji birimine yönlendirildi. 


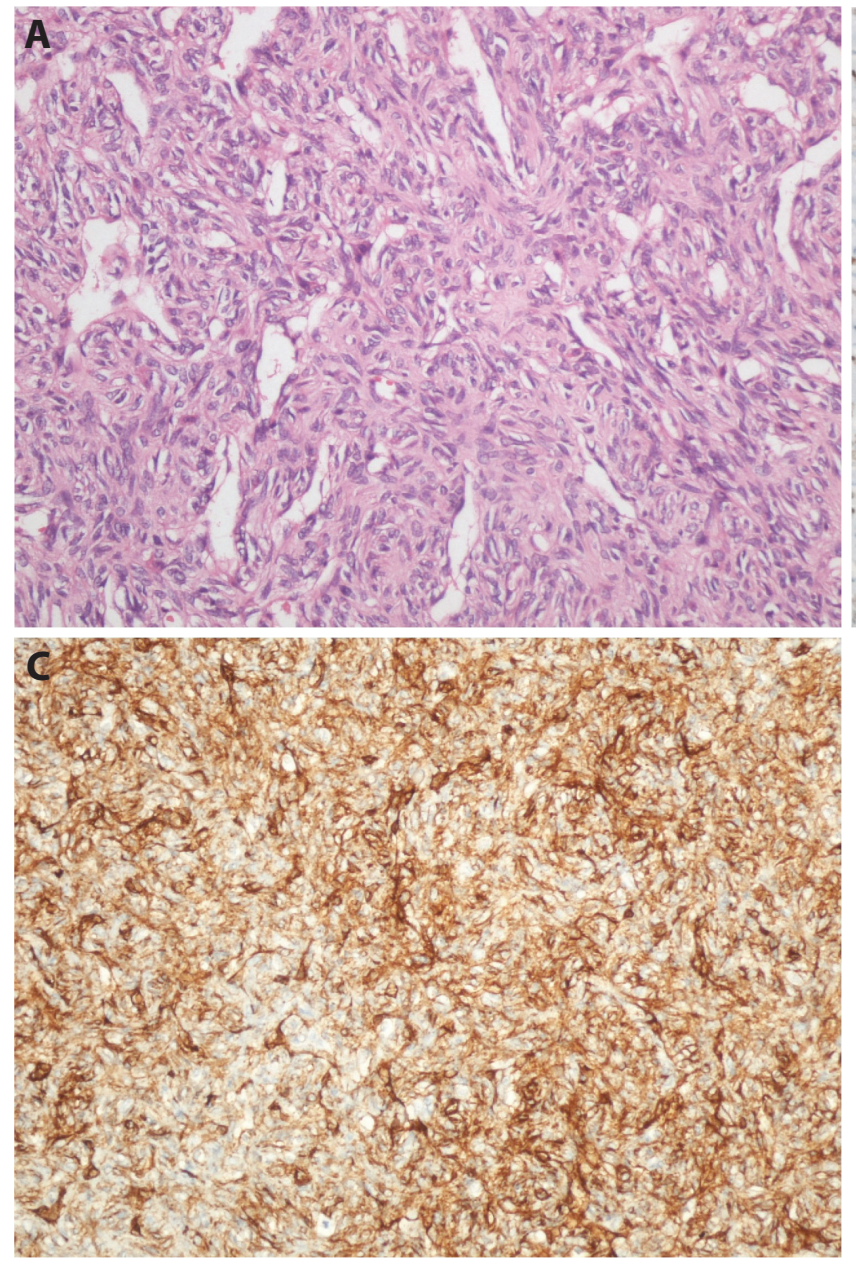

\section{Tartışma}

Hemanjioperisitomalar malign yumuşak doku tümörleri arasında yer alırlar. Lokal agresiften hematojen yolla uzak metastaz yapan ileri derece malign bir spektruma kadar uzanan formları bulunur. Baş-boyun bölge hemanjioperisitomaları daha çok çocukluk çağında görülmekle birlikte; genelinde 45-55 yaş arası daha sık gözlenirler (1).

Bu tümörler, invaziv ve vaskülarizasyon açısından oldukça zengin olduğundan nüks oranı yüksektir ve sıklıkla metastaz yaparak hastaların sağ kalım sürelerini kısaltırlar. Ayrıca ileri derece vasküler yapıda olması tümörün radikal rezeksiyonunu da zorlaştırır. Tümörün rezidü bırakılmadan tamamının radikal olarak rezeksiyonu ile sonuçlanan vakalarda sağ kalım süresi diğer vakalara göre oldukça yüksektir (4).

Hemanjioperisitomalar nadir görülen tümörlerdir. Lokal görülen türleri bası semptomu oluşturana kadar farkedilmeyebilir. Multifokal formları özellikle çocukluk çağında metastaz ile karıştırılabilir. Tedavinin öncesinde ayrıntılı muayene, tümörün boyutunu belirleyerek tedaviyi

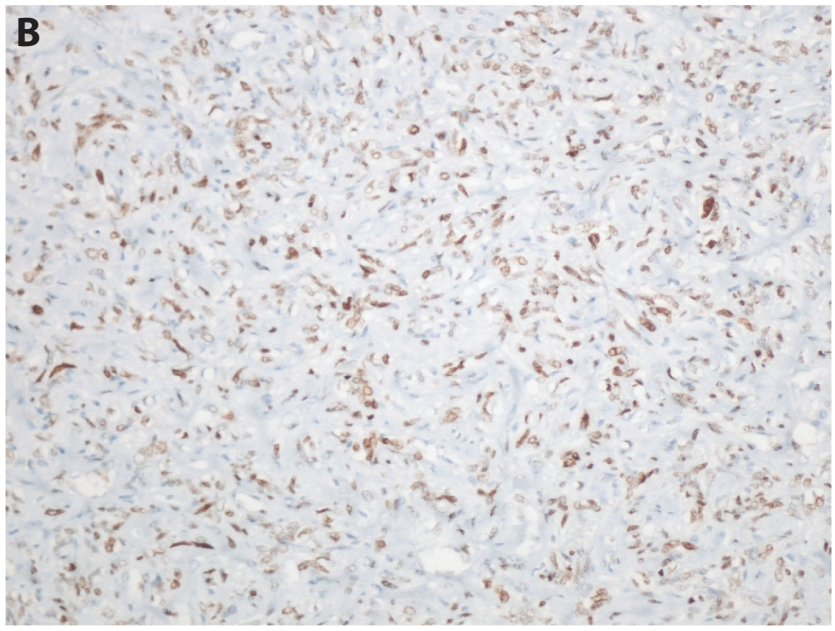

Şekil 3. a-c. Tümöral kitlenin histopatolojik görüntüsü. İnceleme sonucu hemanjioperisitoma (soliter fibröz tm) ile uyumlu gelmiştir. Geyik boynuzu biçiminde dallanmış damarlar arasında uzanan iğsi hücreler. Işaretlenmiş hipersellüler görünüm; H\&E boyama, \%2cx20png (a). İmmunohistokimyasal inceleme; hücresel STAT-6 tutulumu, \%2cx20png (b). İmmunohistokimyasal inceleme; yaygın CD-34 pozitifliği, \%2cx20png (c).

Video: Preoperatif BT anjiyografi görüntüsünde femoral kitlenin sınırları, femoral arter ve ven ile olan komşuluğu ve kitleyi besleyen vasküler dallar görülmektedir.

planlamada yardımcı olur. Diagnostik anjiyografi ve BT anjiyografi tümörün vasküler paternini gösterir, manyetik rezonans görüntüleme ve ultrason gibi yöntemler de tümörün boyutunu belirleyerek ameliyat öncesi planlamada yardımcı olurlar (3).

Klinik ve radyolojik olarak ortaya konulan teşhis biyopsiyle doğrulanır. Lezyonun histopatolojisi atipik sitolojiden oluşan ve geyik boynu benzeri birçok vaskuler dallanma gösteren fusiform neoplazmadır. İmmunohistokimya çalışmalarında tümör dokusu genellikle CD34 pozitifliği gösterir (3). Nadir görülen bir tümör olan hemanjioperisitomaların kesin tanısı histopatolojik olarak yapılmaktadır. Radyolojik görüntülemeler sonucunda saptanan kitle lezyonun ayrıcı tanısında liposarkom, malign fibröz histiyositom ve leiyomyosarkom bulunmaktadır (5). Her ne kadar iyi belirlenmiş sınırları ile malign fibröz histiyositomdan, hipervaskülaritesi nedeniyle liposarkomdan ayırdedilse de bunlar non-spesifik bulgulardır ve histolojik doğrulamaya ihtiyaç vardır (5). Cerrahi eksizyon semptomları rahatlatmak ve tanıyı doğrulamada en çok tercih edilen metottur (6). 
Radikal rezeksiyon sonucunda tümörün tekrarlama olasılığı oldukça düşüktür. Cerrahi öncesinde kemoterapi kullanımı önerilmekle birlikte, standart bir tedavi yöntemi belirtilmemiştir (7). Literatüre göre tümörün tamamının çıkartılması tavsiye edilen tedavi yöntemidir (8). Bazı vakalarda, özellikle lokal agresif seyreden ve invazyon derecesi fazla olan tümörlerde neoadjuvan tedavi, cerrahi sonuçları iyileştireceğinden tercih edilebilir (3).

Sonuç olarak hemanjioperisitomalar ender görülen tümörlerdir ve alt ekstremite yerleşimli olgu ya da

\section{Kaynaklar}

1. Jaber S, Winer I, Rasool N. Recurrent Omental Hemangiopericytoma: A Therapeutic Challenge. Case Rep Obstet Gynecol 2016;2016:2075157. [CrossRef]

2. Eken KG, Tanriverdi O, Özağarı A, Kabukçuoğlu F. Renal Hemanjiyoperisitom: Olgu Sunumu ve Güncel Hemanjiyoperisitom - Soliter Fibröz Tümör Yaklaşımı. Turkiye Klinikleri J Med Sci 2012;32:1423-8. [CrossRef]

3. Robl R, Carvalho VO, Abagge KT, Uber M, Lichtvan LC, Werner B, Mehrdad Nadji M. Multifocal Congenital Hemangiopericytoma. Pediatr Dermatol 2017;34:e69-73. [CrossRef]

4. Arai N, Takahashi S, Mami H, Tokuda Y, Yoshida K. A case report of surgical management of hemangiopericytoma at the foramen magnum. Surg Neurol Int 2017;8:151. [CrossRef] araştırma makalelerine literatürde nadir rastlanmaktadır. Hastamızda sağ femoral bölgede yerleşimli olan tümörü bası semptomları yaratması ve küratif olması amacıyla cerrahi olarak eksize ettik. Bizim vakamızda olduğu gibi selim seyreden lokal hemanjioperisitoma türlerinde uzun dönem sağ kalım literatürde yüksek olarak bildirilmektedir $(7,8)$. Tümörün nadir olması sebebi ile tekrarlama sıklığı, görülme sıklığı ve metastaz oranları tam bilinmemektedir. Başarılı başlangıç tedavisi ve uzun vadeli izlem ile hemanjioperisitoma vakalarının prognozu daha net olarak anlaşılabilecektir.

5. Resorlu M, Toprak CA, Ozturk MO, Arslan M. Retroperitoneal hemangiopericytoma. BMJ Case Rep 2017;2017. [CrossRef]

6. Chhaidar A, Zouari S, Bdioui A, Mokni M, Ben Ali A. Very rare localization of a retroperitoneal hemangiopericytoma revealed by lumbosciatalgia: A case report. Int J Surg Case Rep 2018;53:127-31. [CrossRef]

7. Pokrowiecki R, Dowgierd K. External carotid artery sacrifice in the treatment of infantile haemangiopericytoma in a neonate. Int J Oral Maxillofac Surg 2017;47:24-6. [CrossRef]

8. Fernandez-Pineda I, Parida L, Jenkins JJ, Davidoff AM, Rao BN, Rodriguez-Galindo C. Childhood hemangiopericytoma: review of St Jude Children's Research Hospital. J Pediatr Hematol Oncol 2011;33:356-9. [CrossRef] 